\title{
Twenty-Five Years of End-User Searching, Part 1: Research Findings
}

\author{
Karen Markey \\ School of Information, 1085 South University Avenue, University of Michigan, Ann Arbor, MI 48109-1107. \\ E-mail: ylime@umich.edu
}

\begin{abstract}
This is the first part of a two-part article that reviews 25 years of published research findings on end-user searching in online information retrieval (IR) systems. In Part 1 (Markey, 2007), the author seeks to answer the following questions: What characterizes the queries that end users submit to online IR systems? What search features do people use? What features would enable them to improve on the retrievals they have in hand? What features are hardly ever used? What do end users do in response to the system's retrievals? Are end users satisfied with their online searches? Summarizing searches of online IR systems by the search features people use everyday makes information retrieval appear to be a very simplistic one-stop event. In Part 2, the author examines current models of the information retrieval process, demonstrating that information retrieval is much more complex and involves changes in cognition, feelings, and/or events during the information seeking process. She poses a host of new research questions that will further our understanding about end-user searching of online IR systems.
\end{abstract}

\section{Introduction}

Twenty-five years have passed since the mass deployment of online catalogs in North American libraries made it possible for end users to conduct independent online searches for information. Prior to 1980, the few available online information retrieval (IR) systems were expensive and complicated to search, so end users either delegated their searches to trained intermediaries or searched card catalogs and print indexes on their own. In the mid 1980s, online IR system suppliers introduced simpler front-end interfaces to online IR systems and marketed search services to end users, but few end users ever used these services because of their high cost. By the late 1980s, end users could go to libraries to search the most popular online IR databases on CD-ROMs or through the online catalog's familiar interface.

Received September 9, 2005; revised January 25, 2006; accepted January 30, 2006

C 2007 Wiley Periodicals, Inc. • Published online 16 April 2007 in Wiley InterScience (www.interscience.wiley.com). DOI: 10.1002/asi.20462
WAIS and GOPHER were among the earliest tools that end users enlisted to search the Internet in the early 1990s. End-user searching truly came into its own with the deployment of Web search engines in the mid-1990s. Doing research for jobs and school, researching products, and searching for political information are typical tasks that Web searchers now do on a daily basis (Pew Research Center, 2005, p. 69). Weekly use statistics from Web search engines dwarf yearly use statistics for online catalogs in libraries. For example, during the month of July 2006, Americans submitted 5.6 billion searches to 60 Web search engines including the popular Google, Yahoo!, MSN, and AOL (Sherman, 2006). Over a 479-day period, Melvyl, the statewide online catalog and database service for the University of California's academic library system, logged a mere 2.5 million searches (Cooper, 2001, p. 137). Thousands of special collections that make up the invisible Web feature their own unique search engines because their content is not accessible via general Web search engines.

Online catalogs are still with us. Today's online catalog features a Web-based interface. Because it is merely one of hundreds of other databases in academic library gateways and one of thousands of Web databases, it is no longer the "jewel in the crown" in terms of end-user searching.

This two-part article summarizes our knowledge of enduser searching of online IR systems based on a review of 25 years of published research findings. In Part 1 (Markey, 2007), I answer these research questions: What characterizes the queries that end users submit to online IR systems? What search features do people use, especially features that would enable them to improve on the retrievals they have in hand? What features are hardly ever used? What do end users do in response to the system's retrievals? Are end users satisfied with their online searches?

Because of my focus on end users, I limit my review to intervention-free studies of user-initiated searches-no observers were present to monitor end-user searching, no researchers assigned tasks to end users, and no interviewers questioned users before, during, or after the search. I was deliberate about this limitation because I wanted to learn 
how end users search online IR systems left to their own devices and unaffected by potential biases such as the presence of an observer, their knowledge that a reviewer would scrutinize their search at a later time, their aptitude for or the potential biases of a researcher-assigned task. Because of my insistence on intervention-free studies, most studies in this review enlist transaction logs to collect end-user search activity. Transaction logs are fraught with their own limitations (Kurth, 1993), chief among them are the severe limits they place on the range and versatility of research questions a person can answer using the method. However, limiting this review to studies that use this approach to data collection serves as a type of control, making it possible to compare findings across studies and to establish a baseline for the search activities that characterize end-user searchers.

In Part 2, I consider answers to these research questions in the context of current models of the information retrieval process. I offer a host of new research questions that will further our understanding about end-user searching of online IR systems. Part 2 concludes with my advice to future IR system developers about retaining the simplicity of online IR system interfaces.

\section{Characterizing End-User Queries}

In this section, the summary statistics that IR researchers report about end-user searches are featured. Unless indicated otherwise, I have limited the studies cited in this section to studies of user-initiated searches in which no observers were present to monitor end-user searching nor did interviewers assign tasks to end users or question them before, during, or after the search.

\section{End-User Searches Bear Few Queries}

Table 1 enumerates the mean number of queries that users enter into online IR systems. In addition, the type of system and notes about special exceptions or conditions are given.

The mean number of queries per end-user search session ranges from a low of 1.9 to a high of 13.8. Most studies report means between two and four queries per session. These two- to four-query sessions are not limited to searches of Web search engines, but include online catalogs and digital libraries.

To date, only one study (Ozmutlu, Spink, \& Ozmutlu, 2004 , pp. 323, 325) has investigated session length at different times of the day. Because the ranges between the

TABLE 1. Mean number of queries per search session.

\begin{tabular}{|c|c|c|c|}
\hline Mean \# queries & System type & Notes & Researcher(s) and citation \\
\hline 13.8 & Norwegian-based web search engine (Fast) & From $10-11$ A.M. & Ozmutlu, Spink, \& Ozmutlu (2004, p. 325) \\
\hline 10.3 & Norwegian-based web search engine (Fast) & Mean \# between 12 A.M. and 11:59 P.M. & Ozmutlu, Spink, \& Ozmutlu (2004, p. 325) \\
\hline $8-9$ & A\&I service (UM Medline aka PaperChase) & & King (1991, p. 365) \\
\hline 7.3 & Web search engine (Excite) & Queries about sex only & Spink, Ozmutlu, \& Lorence (2004, p. 117) \\
\hline 6.6 & Norwegian-based web search engine (Fast) & From 3-4 A.M. & Ozmutlu, Spink, \& Ozmutlu (2004, p. 325) \\
\hline 4.9 & Web search engine (Excite) & & Spink et al. (2001, p. 228) \\
\hline 4.6 & Online catalog (SULIRS) & & Markey (1984, p. 66) \\
\hline 4.2 & Web search engine (Excite) & All but queries about sex & Spink, Ozmutlu, \& Lorence (2004, p. 117) \\
\hline 4.0 & Online catalog (Okapi) & & Mitev, Venner, \& Walker (1985, p. 155) \\
\hline 3.9 & Web search engine (Excite) & Mean \# between 9 and 5 P.M. & Ozmutlu, Spink, \& Ozmutlu (2004, p. 323) \\
\hline 3.9 & Web search engine (Excite) & Request-format queries & Ozmutlu, Ozmutlu, \& Spink (2003, p. 399) \\
\hline 3.4 & Web search engine (Excite) & $1999 \log$; queries for images & Ozmutlu, Spink, \& Ozmutlu (2003, p. 615) \\
\hline 3.3 & Online catalog (LS/2000, ORION, SULIRS) & Searches initiated by a subject search & Drabenstott \& Vizine-Goetz (1994, p. 167) \\
\hline 3.2 & Web search engine (Excite) & $1997 \mathrm{log}$; queries for images & Ozmutlu, Spink, \& Ozmutlu (2003, p. 615) \\
\hline 3.0 & Online catalog (Melvyl) & Melvyl and A\&I databases & Cooper $(2001$, p. 143$)$ \\
\hline 2.9 & Web search engine (Excite) & From 9 A.M. to 5 P.M. & Ozmutlu, Spink, \& Ozmutlu (2004, p. 323) \\
\hline 2.9 & Web search engine (Excite) & $1997 \log$; queries for video & Ozmutlu, Spink, \& Ozmutlu (2003, p. 615) \\
\hline 2.9 & European web search engine (AlltheWeb) & Question-format queries & Ozmutlu, Ozmutlu, \& Spink (2003, p. 399) \\
\hline 2.9 & European web search engine (AlltheWeb) & Request-format queries & Ozmutlu, Ozmutlu, \& Spink (2003, p. 399) \\
\hline 2.8 & Web search engine (Excite) & "51K" log & $\begin{array}{l}\text { Jansen, Spink, \& Saracevic (2000, p. 212); } \\
\text { Jansen et al. (1998, p. 9) }\end{array}$ \\
\hline 2.8 & Web search engine (Excite) & $2001 \mathrm{log}$; queries for images & Ozmutlu, Spink, \& Ozmutlu (2003, p. 615) \\
\hline 2.7 & Web search engine (Excite) & Queries for business topics & Spink, \& Gunar (2001) \\
\hline 2.6 & Web search engine (Excite) & $2001 \log$; queries for audio & Ozmutlu, Spink, \& Ozmutlu (2003, p. 615) \\
\hline 2.6 & Web search engine (Excite) & $2001 \log$; queries for video & Ozmutlu, Spink, \& Ozmutlu (2003, p. 615) \\
\hline 2.5 & Web search engine (Excite) & $1997 \log$ & Spink et al. (2002, p. 108) \\
\hline 2.4 & Web search engine (Excite) & $1997 \log$; queries for audio & Ozmutlu, Spink, \& Ozmutlu (2003, p. 615) \\
\hline 2.3 & Web search engine (Excite) & Question-format queries & Ozmutlu, Ozmutlu, \& Spink (2003, p. 399) \\
\hline 2.3 & Web search engine (Excite) & $2001 \log$ & Spink et al. (2002, p. 108) \\
\hline 2.2 & Web search engine (Excite) & From 4 to 5 P.M. & Ozmutlu, Spink, \& Ozmutlu (2004, p. 323) \\
\hline 2.0 & Digital library (NZDL's CSTR collection) & & Jones et al. $(2000$, p. 159$)$ \\
\hline 2.0 & Web search engine (Alta Vista) & & Silverstein et al. (1999, p. 8) \\
\hline 1.9 & Web search engine (Excite) & $1999 \log$ & Spink et al. (2002, p. 108) \\
\hline
\end{tabular}


longest and shortest sessions using the search engines, Fast (13.8 and 6.6) and Excite (3.9 and 2.2), respectively, were dramatically different, the characteristics of the system may affect session length. Unfortunately, the Fast-Excite study's authors comment neither on the search characteristics of Fast or Excite nor on the people who query these two systems to give readers insight into the reasons why Fast sessions are so lengthy in comparison to Excite. Its authors do comment on lengthy sessions in which end users enter queries on sex (Spink, Ozmutlu, \& Lorence, 2004), remarking on how the stimulating and satisfying nature of the task may make searchers more "willing to expend more time and effort in pursuit of their information need than general Web searchers" (p. 121). King (1991, p. 370) follows up her report of sessions bearing eight to nine queries by telling how PaperChase monitors searches and suggests improvements to users. Thus, the high number of PaperChase queries per session is the result of users' positive responses to PaperChase's advice regarding substituting their free-text terms with MeSH (Medical Subject Headings), the controlled vocabulary of PaperChase's Medline database, and PaperChase's subsequent searches for the substituted $\mathrm{MeSH}$

An alternate approach to reporting session length is to give the percentages of end users whose sessions bear one search statement only, two search statements, and more than three search statements (Table 2). Null queries account for user actions such as hitting the $<$ RETURN $>$ on the keyboard only.

Except for searches on sex topics, the sessions' users conduct in search engines are very brief, with the majority of sessions consisting of one or two queries. Over two decades ago, Borgman (1983) acknowledged that session length in Ohio State's Library Control System (LCS) online catalog was "highly skewed to the left" (p. 23). Seeking an explanation for the phenomenon, she concludes that sessions bearing known-item searches for author names, titles, and combination author-title data are shorter and sessions bearing subject searches are longer in terms of numbers of queries. Web search engines do not allow users to distinguish subject queries from other types, so IR researchers have not arrived at the same conclusion. Perhaps, additional in-depth studies of queries by topic (e.g., sex in Spink, Jansen, Wolfram, \& Saracevic, 2002) or discipline (e.g., business by Spink \& Gunar, 2001) may disclose the reasons for such short sessions.

\section{End-User Search Statements Bear Few Terms}

Table 3 enumerates the mean number of terms in the queries that users enter into online IR systems. Included are the type of system and notes about special exceptions or conditions.

The ordering in Table 3 by mean number of terms per query yields these insights: (a) except for Melvyl, the shortest queries - between one and two words - are entered into online catalogs; (b) longer queries come from general Web search engines, but they are still not especially wordy averaging between two and three words; (c) in the middle of the pack are queries for special topics, e.g., business topics, sex, and various multimedia formats, and (d) the longest queries are request- and question-format queries from Web search engines, averaging between four and eight terms.

An alternate approach to reporting query length is to give the percentages of end users whose sessions are null, bear one term, two terms, and three or more terms (Table 4).

Table 4 presents a variety of results. Examining Web search logs, some researchers report large percentages of one-word queries; others report roughly the same percentages across the board. Anything is possible with respect to online catalogs. Because users enter lengthy queries using MUMS' (an online catalog) find and Melvyl's lookup searches (bottom of Table 4), one could speculate that end users enter lengthy queries when they know that the system is performing a keyword search with an implicit Boolean AND operation on the terms they enter. This explanation does not work because end users frequently choose Scorpio's (an online catalog) find capability, also a keyword search, to enter one-word queries (top of Table 4). Almost all online catalog studies date back a decade or more, so we are due for updated transaction log analyses to see if the queries end users enter into these systems are now comparable in length to Web queries.

\section{Using the Search Features of Information Retrieval Systems}

Because IR researchers do not report findings about advanced search features in a systematic way, they cannot be summarized in a table. As an alternative for reporting findings, I will present the claims made about advanced search features and discuss the studies that support and fail to support each claim. Included are studies in which end users are

TABLE 2. Percentages of queries per search session.

\begin{tabular}{lcccccc}
\hline$\%$ Null & $\%$ 1 Term & $\%$ 2 Terms & $\%>3$ Terms & \multicolumn{1}{c}{ System type } & Notes \\
\hline NA & 77.6 & 13.5 & 9.9 & Web search engine (Alta Vista) & Silverstein et al. (1999, p. 10) \\
0.5 & 67.0 & 19.0 & 13.5 & Web search engine (Excite) & Jansen, Spink, \& Saracevic (2000, p. 212) \\
1.9 & 48.4 & 20.8 & 31.0 & Web search engine (Excite) & Spink et al. (2001, p. 228) \\
NA & 30.1 & 36.5 & 33.4 & Online catalog (Okapi) & Mitev, Venner, \& Walker (1985, p. 208) \\
NA & 24.3 & 19.1 & 56.5 & Web search engine (Excite) & Queries about & Spink, Ozmutlu, \& Lorence (2004, p. 117) \\
& & & & & sex only \\
\hline
\end{tabular}


TABLE 3. Mean number of terms per query.

\begin{tabular}{|c|c|c|c|}
\hline Mean \# of terms & System type & Notes & Researcher(s) and citation \\
\hline 7.8 & Web search engine (Excite) & Question-format queries & Spink \& Ozmutlu (2002, p. 457) \\
\hline 7.8 & Web search engine (Excite) & $\begin{array}{l}\text { Question-format queries for business } \\
\text { topics }\end{array}$ & Spink \& Gunar (2001) \\
\hline 7.0 & Web search engine (Excite) & Question-format queries & Ozmutlu, Ozmutlu, \& Spink (2003, p. 401) \\
\hline 7.0 & Web search engine (Ask Jeeves) & Question-format queries & Spink \& Ozmutlu (2002, p. 458) \\
\hline 5.0 & European web search engine (AlltheWeb) & Question-format queries & Ozmutlu, Ozmutlu, \& Spink (2003, p. 401) \\
\hline 4.8 & Online catalog (Melvyl) & Using Melvyl's look-up capability & Larson $(1983$, p. 51) \\
\hline 4.3 & Web search engine (Excite) & Queries for audio & Ozmutlu, Spink, \& Ozmutlu (2003, p. 616) \\
\hline 4.1 & Web search engine (Excite) & Request-format queries & Ozmutlu, Ozmutlu, \& Spink (2003, p. 401) \\
\hline 3.9 & Online catalog (Melvyl) & Using Melvyl's command capability & Larson (1983, p. 52) \\
\hline 3.7 & Web search engine (Excite) & All but queries about sex & Spink, Ozmutlu, \& Lorence (2004, p. 117) \\
\hline 3.7 & Web search engine (Excite) & Queries for multimedia & Ozmutlu, Spink, \& Ozmutlu (2003, p. 616) \\
\hline 3.7 & Web search engine (Excite) & Queries for video & Ozmutlu, Spink, \& Ozmutlu (2003, p. 616) \\
\hline 3.6 & Web search engine (Excite) & Queries for images & Ozmutlu, Spink, \& Ozmutlu (2003, p. 616) \\
\hline 3.5 & Web search engine (Excite) & Queries for business topics & Spink \& Gunar (2001) \\
\hline 3.3 & European web search engine (AlltheWeb) & Request-format queries & Ozmutlu, Ozmutlu, \& Spink (2003, p. 401) \\
\hline 3.1 & Norwegian web search engine (Fast) & From 5-6 A.M. & Ozmutlu, Spink, \& Ozmutlu (2004, p. 332) \\
\hline 2.9 & Web search engine (Excite) & Queries about sex & Spink, Ozmutlu, \& Lorence (2004, p. 117) \\
\hline 2.8 & Online catalog (MUMS) & Using MUMS' find capability & Larson $(1983$, p. 48) \\
\hline 2.8 & Online catalog (LUIS 3.3) & & Larson (1983, p. 46) \\
\hline 2.6 & Web search engine (Excite) & From 12-1 P.M. & Ozmutlu, Spink, \& Ozmutlu (2004, p. 331) \\
\hline 2.6 & Digital library (NZDL's CSTR collection) & Using CSTR's Boolean search capability & Jones et al. $(2000$, p. 156$)$ \\
\hline 2.5 & Norwegian web search engine (Fast) & From 12 A.M. to $11: 59$ P.M. & Ozmutlu, Spink, \& Ozmutlu (2004, p. 332) \\
\hline 2.4 & Web search engine (Excite) & From 9 A.M. to 5 P.M. & Ozmutlu, Spink, \& Ozmutlu (2004, p. 331) \\
\hline 2.4 & Web search engine (Excite) & "1M log" & Spink et al. (2001, p. 228) \\
\hline 2.4 & Web search engine (Alta Vista) & & Silverstein et al. (1999, p. 8) \\
\hline 2.4 & Web search engine (Excite) & "51K log" & Jansen et al. (1998, p. 9) \\
\hline 2.2 & Web search engine (Excite) & From 4-5 P.M. & Ozmutlu, Spink, \& Ozmutlu (2004, p. 331) \\
\hline 2.2 & Web search engine (Excite) & & Jansen, Spink, \& Saracevic (2000, p. 214) \\
\hline 2.2 & $\begin{array}{l}\text { Digital library (NZDL's CSTR } \\
\text { collection) }\end{array}$ & $\begin{array}{l}\text { Using CSTR's natural-language search } \\
\text { capability }\end{array}$ & Jones et al. $(2000$, p. 156$)$ \\
\hline 2.2 & Online catalog (Okapi) & & Mitev, Venner, \& Walker (1985, p. 208) \\
\hline 2.1 & $\begin{array}{l}\text { Online catalog (LS/2000, SULIRS, } \\
\text { and ORION) }\end{array}$ & $\begin{array}{l}\text { Initial subject queries in subject searches } \\
\text { that match first word of subject headings }\end{array}$ & Drabenstott \& Vizine-Goetz (1994, p. 207) \\
\hline 2.1 & Online catalog (Scorpio) & Using Scorpio's browse capability & Larson (1983, p. 49) \\
\hline 1.8 & Norwegian web search engine (Fast) & From 6-7 A.M. & Ozmutlu, Spink, \& Ozmutlu (2004, p. 332) \\
\hline 1.8 & $\begin{array}{l}\text { Local academic search engine } \\
\quad \text { (University of Tennessee web site) }\end{array}$ & & Wang, Berry, \& Yang (2003, p. 747) \\
\hline 1.8 & $\begin{array}{l}\text { Online catalog (LS/2000, SULIRS, } \\
\text { and ORION) }\end{array}$ & $\begin{array}{l}\text { Initial subject queries in subject } \\
\text { searches only }\end{array}$ & Drabenstott \& Vizine-Goetz (1994, p. 167) \\
\hline 1.8 & Online catalog (Ulisys) & & Larson (1983, p. 42) \\
\hline 1.7 & Online catalog (Scorpio) & Using Scorpio's find capability & Larson (1983, p. 48) \\
\hline 1.4 & $\begin{array}{l}\text { Online catalog (LS/2000, SULIRS, } \\
\text { and ORION) }\end{array}$ & $\begin{array}{l}\text { Initial subject queries in subject searches } \\
\text { that match subject headings }\end{array}$ & Drabenstott \& Vizine-Goetz (1994, p. 169) \\
\hline 1.3 & $\begin{array}{l}\text { Online catalog (LS/2000, SULIRS, } \\
\text { and ORION) }\end{array}$ & $\begin{array}{l}\text { Initial subject queries in subject searches } \\
\text { that name places }\end{array}$ & Drabenstott \& Vizine-Goetz (1994, p. 186) \\
\hline
\end{tabular}

given instruction in system use prior to observation because some interesting trends emerge. Only a few studies cite online catalogs because advanced search features connected with Boolean searching were not deemed necessary to search for the few author names, titles, and subject headings in machinereadable cataloging (MARC) records (Hildreth, 1983).

1. Less than $15 \%$ of queries in end-user searches bear the Boolean AND operator.

Supporting this claim are eight studies. Six studies examine the queries users enter into Web search engines (Hölscher \& Strube, 2000, p. 345; Jansen, Spink, \& Saracevic, 2000, p. 217;
Keily, 1997, p. 206; Lucas \& Topi, 2002, p. 100; Spink \& Ozmutlu, 2002, p. 459; Spink et al., 2002, p. 108). Only one study each of queries in online catalogs (Peters, 1989, p. 269) and digital libraries (Jones, Cunningham, McNab, \& Boddie, 2000, p. 166) exists. Percentages go as low as less than $1 \%$ (Peters, 1989, p. 269).

Failing to support this claim are a dozen studies. Three of the 12 studies report percentages that exceed 15\% (Bishop et al., 2000, p. 404; Miller, Kirby, \& Templeton, 1988, p. 7; Siegfried, Bates, \& Wilde, 1993, p. 279; Wildemuth \& Moore, 1995, p. 299). The rest report frequent use of the Boolean AND operator in a variety of ways that would appear to exceed the $15 \%$ cited in this claim. Seven of 12 studies examine 
TABLE 4. Percentages of queries of varying lengths.

\begin{tabular}{|c|c|c|c|c|c|c|}
\hline$\%$ Null & $\% 1$ Term & $\% 2$ Terms & $\%>3$ Terms & System type & Notes & Researcher(s) and citation \\
\hline NA & 63.3 & 19.1 & 17.6 & Online catalog (Scorpio) & Using Scorpio's find capability & Larson $(1983$, p. 48$)$ \\
\hline NA & 52.0 & 33.0 & 15.0 & Online catalog (LUIS) & & Lester (1989) \\
\hline NA & 50.0 & 20.0 & 29.0 & Web search engine (Excite) & & Spink et al. $(2002$, p. 107) \\
\hline NA & 49.2 & 32.1 & 18.8 & Online catalog (Ulisys) & & Larson (1983, p. 42) \\
\hline NA & 38.8 & 41.5 & 19.6 & $\begin{array}{l}\text { Local academic search engine } \\
\text { (University of Tennessee web site) }\end{array}$ & & $\begin{array}{l}\text { Wang, Berry, \& Yang } \\
\quad(2003 \text {, p. } 747)\end{array}$ \\
\hline NA & 37.4 & 35.4 & 27.2 & Online catalog (Scorpio) & Using Scorpio's browse capability & Larson (1983, p. 49) \\
\hline NA & 30.1 & 36.5 & 33.4 & Online catalog (Okapi) & & $\begin{array}{l}\text { Mitev, Venner, \& Walker } \\
\quad(1985,208)\end{array}$ \\
\hline 1.6 & 27.1 & 34.0 & 37.3 & $\begin{array}{l}\text { Digital library (NZDL's } \\
\text { CSTR collection) }\end{array}$ & $\begin{array}{l}\text { Using CSTR's natural-language } \\
\text { search capability }\end{array}$ & Jones et al. (2000, p. 156) \\
\hline 20.6 & 25.8 & 26.0 & 27.6 & Web search engine (Alta Vista) & & Silverstein et al. (1999, p. 9) \\
\hline NA & 24.3 & 37.0 & 38.7 & Online catalog (Melvyl) & Using Melvyl's command capability & Larson (1983, p. 52) \\
\hline 1.7 & 21.8 & 34.5 & 42.0 & $\begin{array}{l}\text { Digital library (NZDL's } \\
\text { CSTR collection) }\end{array}$ & $\begin{array}{l}\text { Using CSTR's Boolean search type } \\
\text { capability }\end{array}$ & Jones et al. (2000, p. 156) \\
\hline NA & 9.4 & 38.3 & 52.3 & Online catalog (LUIS 3.3) & & Larson $(1983$, p. 46) \\
\hline NA & 8.4 & 42.9 & 48.7 & Online catalog (MUMS) & Using MUMS' find capability & Larson $(1983$, p. 48$)$ \\
\hline NA & 1.5 & 27.5 & 71.0 & Online catalog (Melvyl) & $\begin{array}{l}\text { Using Melvyl's lookup mode } \\
\text { capability }\end{array}$ & Larson (1983, p. 51) \\
\hline
\end{tabular}

A\&I (abstracting and indexing) databases, and in six of them, end users are given training in use of the A\&I retrieval system prior to an observational or experimental study (Sewell \& Teitelbaum, 1986, p. 236; Siegfried et al., 1993, p. 275; Sutcliffe, Ennis, \& Watkinson, 2000, p. 1213; Trzebiatowski, 1984, p. 447; Vakkari, Pennaman, \& Serola, 2003, p. 451; Wildemuth \& Moore, 1995, p. 295). Not only does Mead, Sit, Rogers, Jamieson, and Rousseau (2000, p. 110) give endusers training in online catalog searching, but the tasks that they give to end users cite the very Boolean operators that yield relevant retrievals. In the five remaining studies, end users do not receive training in the use of Medline in A\&I systems (King, 1991, p. 366; Kirby \& Miller, 1986, p. 23; Miller et al., 1998, p. 7), in an online catalog that accesses both MARC and A\&I databases (Cooper, 2001, p. 143), and in a digital library (Bishop et al., 2000, p. 404).

2. Less than $3 \%$ of queries in end-user searches bear the Boolean OR operator.

Twelve studies support this claim. Six studies report percentages under $0.5 \%$ of queries. Represented are the wide range of online IR systems: (a) the Web search engines Excite (Jansen et al., 2000, p. 217; Spink \& Ozmutlu, 2002, p. 459), Ask Jeeves (Spink \& Ozmutlu, 2002, p. 459), and users' choice (Lucas \& Topi, 2002, p. 100); (b) A\&I databases, especially Medline (Hsieh-Yee, 1993, p. 166; King, 1991, p. 370; Rudner, 2000; Sewell \& Teitelbaum, 1986, p. 240; Vakkari et al., 2003, p. 455; Wildemuth \& Moore, 1995, p. 299); (c) an online catalog (Peters, 1989, p. 269), and (d) a digital library (Jones et al., 2000, p. 156). Of the six studies that examine A\&I databases, three of them tell about the training end users receive prior to an observational or experimental study (Sewell \& Teitelbaum, 1986, p. 236; Vakkari et al., 2003, p. 451; Wildemuth \& Moore, 1995, p. 295).
Instead of reporting percentages, Hsieh-Yee (1993, p. 166) reports significantly greater numbers of OR operators in the queries of system experts than in the queries of end users. Similarly, Rudner (2000) counts 5 to 20 times the number of ORs in the searches of expert searchers of the ERIC (Educational Resources Information Center) database than in the searches of end users.

Seven studies fail to support the claim. Five examine A\&I databases, and two examine online catalogs. Four of the seven studies report on giving end users training in system use prior to an observational or experimental study. When studies cite percentages, they are not much higher than percentages in supporting studies. For example, less than $10 \%$, and $8 \%$ of queries of Compact Cambridge Medline searches and searches of Dialog databases bear the OR operator (Miller et al., 1988, p. 7; Siegfried et al., 1993, p. 279), respectively. Of the 7.8 connectors Debowski (2001, p. 376) counts in Silverplatter ERIC searches, 1.3 are OR operators. Trzebiatowski (1984, p. 448) finds 5 of 20 end users using ORs in their searches of BRS/Afterdark databases and Kirby and Miller (1986, p. 23) find 8 of 27 end users using ORs in their searches of BRS Colleague databases in the health sciences. Cooper (2001, p. 143) counts 1.5 OR operators per search in searches that average three queries. Of the four types of searches Mead et al. (2000, p. 226) assigns to end users, most users use the OR operator in the one search that requires this operator.

3. Less than $2 \%$ of queries in end-user searches bear the Boolean NOT operator.

Seven studies support the claim. When these studies cite percentages, they are miniscule- $0.0003 \%$ of Excite queries (Spink \& Ozmutlu, 2002, p. 459), 0.020\% of Ask Jeeves queries (Spink \& Ozmutlu, 2002, p. 459), 0.20\% of Excite 
queries (Jansen et al., 2000, p. 217), 0.20\% of Medline searches (Wildemuth \& Moore, 1995, p. 299), and $0.70 \%$ of queries in the computer science technical reports (CSTR) digital library (Jones et al., 2000, p. 156). Despite receiving training in A\&I system use, no users enter NOT operators in studies by Trzebiatowski (1984, p. 448) and Siegfried et al. (1993, p. 279).

Two studies fail to support the claim. Lucas and Topi (2002, p. 100) report $2.7 \%$ of the queries users enter into a Web search engine of their choice use NOT operators. Cooper (2001, p. 143) counts 1.3 NOT operators per online catalog search in searches that average about three queries.

4. Less than $20 \%$ of queries in end-user searches bear Boolean operators.

This claim covers studies whose authors do not identify the exact types of Boolean operators users enter into online IR systems, so they could not be included in claims \#1 to \#3 above. Six analyses provide evidence to support this claim. Two fail to support it.

With regard to supporting studies, Keily (1997, p. 206) reports the $12.4 \%$ of Magellan queries and $12.2 \%$ of Webcrawler queries use Boolean operators. Examining online activity in Web search engines of choice, Lucas and Topi (2002, p. 100) count 0.63 Boolean operators in end-users' searches versus 2.66 Boolean operators in the searches of expert searchers. Similarly, Hsieh-Yee (1993, p. 166) counts significantly greater numbers of advanced search features, e.g., Boolean operators, proximity operators, and limit statements, in system experts' searches than in end-users' searches of Dialog's ERIC database.

Barely failing to support the claim is Silverstein et al.'s (1999, p. 9) report of the $20.4 \%$ of end-user queries in the Alta Vista Web search engine that bear Boolean operators. Although Debowski (2001, p. 376) reports many connectors (7.8) in end-user searches of Silverplatter's ERIC database, the searchers in her study receive training and practice in system use prior to her observation.

5. End users use syntax for Boolean searching from other systems.

Two studies report this phenomenon in which users enter search statements using syntax that is accepted practice in one system but not in the system they are currently searching. Wang, Berry, and Yang (2003, p. 755) study user activity in an academic Web site's search engine and Jones et al. (2000, p. 165) study the CSTR digital library.

6. Occurrences of the plus (+) and minus (-) operators combined are more common than all three Boolean operators combined in end-users' Web searches.

Because Web search engines introduced both plus and minus operators, studies cite use of Web search engines only.
Four analyses support the claim for searches in Excite (Spink \& Ozmutlu, 2002, p. 459), Ask Jeeves (Spink \& Ozmutlu, 2002, p. 459), Fireball (Hölscher \& Strube, 2000, p. 345), and a Web search engine of the user's choice (Lucas \& Topi, 2002, p. 100). The difference between percentages ranges from seven-tenths of a point to about 10 percentage points.

One study fails to support by barely one-tenth of a point (Jansen et al., 2000, p. 217).

7. Less than $10 \%$ of user queries enlist relevance feedback.

All four studies support this claim. Relevance feedback in a Web searching context usually entails users scanning a retrieved item and clicking on an accompanying system prompt such as "find similar" or "more like this" to which the system responds by applying its proprietary search algorithm to find additional items based on elements (such as unique and frequently occurring keywords and phrases) that both the original item and newly retrieved items have in common. Although one of the earliest online catalogs featured such feedback (Doszkocs, 1983), relevance feedback is more common in Web search engines. Relevance feedback occurs in 9.7\% (Spink \& Ozmutlu, 2002, p. 459) and 5\% (Jansen et al., 2000 , p. 216) of Excite queries and in $0.02 \%$ of Ask Jeeves queries (Spink \& Ozmutlu, 2002, p. 459). Of the 27,000 searchers who search the ERIC database on the Web during a typical month, "only a handful" use the system's "more-like" function that takes descriptors from a relevant citation and recycles them into a new search (Rudner, 2000).

8. Less than $15 \%$ of user queries enclose bound phrases with quotes.

Web search engines introduced searching bound phrases with quotes, and all five studies pertaining to this claim examine Web search engines. Percentages in the four analyses supporting this claim from high to low are $10.1 \%$ of Webcrawler queries (Keily, 1997, p. 206), 8.9\% in Magellan queries (Keily, 1997, p. 206), 6\% of Excite queries, 5\% of Excite question-format queries (Spink \& Ozmutlu, 2002, p. 459), and $1 \%$ of Ask Jeeves question-format queries (Spink \& Ozmutlu, 2002, p. 459).

The one study failing to support this claim cites percentages ranging from 18.5 to $37.0 \%$ in the Fireball Web search engine (Hólscher \& Strube, 2000, p. 345).

\section{Truncation occurs in less than $5 \%$ of end-user searches.}

Of the five studies that examine truncation, three support this claim. Kern-Simirenko (1983, p. 32) notes that only $0.7 \%$ of online catalog queries use truncation. Peters (1989, p. 271) asserts, "Rarely [i]s user-initiated truncation evident in the transaction log" of the LUMIN online catalog. In Trzebiatowski's (1984, p. 448) observational study of searchers using BRS/Afterdark databases, 5 of 20 searchers attempt truncation, and 2 do it incorrectly. 
Two studies of A\&I databases report large percentages (42\% and $30.1 \%$ ) of queries bearing truncation (Miller et al., 1988, p. 7; Siegfried et al., 1993, p. 283), respectively.

10. In end-user searches, nested Boolean logic is uncommon.

Only two studies report on nested Boolean, i.e., the use of parentheses to override operator precedence. Both studies cite low percentages $(0.5 \%$ and $2.7 \%$ ) of occurrences (Jansen et al., 2000, p. 217; Jones et al., 2000, p. 156), respectively.

\section{Most end users accept the IR system's default values.}

Online IR systems offer end users many options for changing the system's default values and personalizing the system's response. Three IR researchers confirm that users rarely take advantage of personalization and accept the system's default values (Bishop et al., 2000, p. 404; Cooper, 2001, p. 143; Jones et al., 2000, p. 155). Qualifying online searches by year, review articles, subheadings, and language is done by 40 to $90 \%$ of PaperChase users because this system's interface guides them through a script that routinely asks them to set these parameters (King, 1991, p. 366).

12. When end users use advanced search features in their queries, they use them incorrectly about a third of the time.

Of the six analyses that address this claim, four support and two fail to support it. Supporting are the statistics that Spink and Ozmutlu (2002, p. 459) cite with regard to the plus (+) and minus ( - ) operators in Excite and Ask Jeeves Web search engines, and the statistics Jansen et al. (2000, p. 217) cite with regard to the Boolean AND and NOT operators and both plus and minus operators. Miller et al. (1988, p. 7) cite an overall $37 \%$ error rate for the use of advanced search features in Compact Cambridge Medline searches.

Error rates for the Boolean OR operator and quotes are not as high as the claim's rate (Jansen et al., 2000, p. 217). Between 92 and $100 \%$ of end users correctly specify AND and OR operators in online catalog searches (Mead et al., 2000, p. 116); however, these percentages may overestimate end-users' understanding of Boolean operators because interviewers gave users the appropriate Boolean operator in the task descriptions of their observational study.

\section{Responding to Retrievals}

In response to the queries users enter into online IR systems, systems respond with a report of the total number of retrieved items and the first page of intermediate results. Typically, intermediate results pages list 10-20 short entries for retrieved material. The types of information given for each entry are meant to give searchers an idea of the item's content so that they can decide whether to fetch the item from the library's bookshelves or, in the case of Web pages, some A\&I databases, and digital library collections, link to the full-text item itself.

Results displays represent between 38 and $60 \%$ of online catalog use activity (38.1\% in LCS, Borgman, 1983, p. 17; about 59\% in LUIS 3.3, Larson, 1983, pp. 27-28; $42 \%$ in SULIRS, Tolle, 1983, p. 47; 49.6\% in Ulisys, Larson, 1983, p. 25; about $49 \%$ in Melvyl, Larson, 1983, pp. 32-33). A surprisingly low $13.3 \%$ of online catalog use activity occurs in the display state at Dallas Public Library (Tolle, 1983, p. 68). As the number of retrievals increase, users are less likely to display them. For example, when an experimental online catalog retrieves five or fewer items, $94 \%$ of end users enter commands to display one or more full entries bearing full bibliographic information. These percentages plunge to $55 \%$ when this same catalog retrieves over 200 entries (Markey \& Demeyer, 1986, p. 277). Studying the transaction logs of the LUIS online catalog at the University of Illinois Chicago, IR researchers make the following observations: (a) when endusers' searches retrieve less than 30 retrievals, users display all hits, (b) when searches yield 30 to 200 retrievals, users generally persist in displaying retrievals, and (c) overload occurs at more than 200 retrievals at which time users do not display entries (Wiberley, Daugherty, \& Danowski, 1993, pp. 11, 51). Jones et al. (2000, p. 162) observe the same behavior from digital library users. When there are 50 or fewer retrievals, $89 \%$ of users link to one or more listed Web pages. When retrievals exceed 200 , only $8 \%$ of users link to one or more Web pages.

When studies of Web search engines discuss retrievals, it is sometimes unclear whether they are referring to the number of intermediate results pages users scan or the links users make to Web sites listed on such pages. Table 5 lists statistics for intermediate results pages. Just in case these studies refer to linked Web pages, Table 5 reiterates the terminology used in cited studies. Except for the Silverstein study on Alta Vista, all studies in Table 5 examine the Excite Web search engine.

Except for Web users searching sex topics, few scan past the second page of intermediate results. Because transaction $\log$ analyses do not include the out-loud thoughts of end users, IR researchers can only speculate what users have in mind when they stop after two pages. Perhaps perseverance wanes after the second page, users have no need to continue because ranking algorithms do such a good job at placing links to relevant retrieved Web pages on top, or they turn to an alternative to Web search engines to satisfy their information needs.

Additional insight into the retrievals that end users display comes from experiments and observations. Drabenstott (2003) observes undergraduate students using the University of Michigan Library (UML) gateway, a portal for the online catalog, A\&I, and both general and specialized Web search engines, and codes each user action into one of nine different states, e.g., authorizing, searching, waiting, reading, and printing states. Per session, users average 93 states of which 37 states are connected with retrievals-viewing-selecting intermediate results (27 states), reading retrieved Web page 
TABLE 5. Number of intermediate result pages in Web search engines.

\begin{tabular}{|c|c|c|}
\hline \# Web pages & Notes & Researcher(s) and citation \\
\hline Viewed more than 20 pages of Web sites & $\begin{array}{l}\text { Queries about } \\
\text { sex only }\end{array}$ & Spink, Ozmultu, \& Lorence (2004, p. 120) \\
\hline $\begin{array}{l}\text { Mean number of pages examined per } \\
\text { user was } 2.4 .58 \% \text { of users did not } \\
\text { access results past the first page. }\end{array}$ & & Jansen, Spink, \& Saracevic (2000, p. 214) \\
\hline $\begin{array}{l}\text { On average users viewed } 2.2 \text { pages. } \\
\text { Half did not access results beyond } \\
\text { the first page. More than three in } \\
\text { four did not go beyond two pages. }\end{array}$ & & Jansen et al. (1998, p. 15) \\
\hline 1.7 pages per query & 1997 Excite $\log$ & Spink et al. (2002, p. 108) \\
\hline 1.7 pages per query & 2001 Excite log & Spink et al. (2002, p. 108) \\
\hline 1.6 pages per query & 1999 Excite log & Spink et al. (2002, p. 108) \\
\hline $\begin{array}{l}\text { Close to half }(47.6 \%) \text { of users looked } \\
\text { at two or fewer pages }\end{array}$ & & Spink et al. (2001, p. 229) \\
\hline $\begin{array}{l}\text { For } 85 \% \text { of queries only the first result } \\
\text { screen is viewed }\end{array}$ & & Silverstein et al. (1999, p. 12) \\
\hline
\end{tabular}

content ( 7 states), and printing promising Web content (3 states) (Drabenstott, 2003, p. 843). The speed with which users pass in and out of states is remarkable. View-select states average 20 seconds and read states average 45 seconds per occurrence. Wallace and Kupperman (1997, p. 14) estimate that middle school students spend about 48 seconds on intermediate results pages and content Web pages to which these results link. Regarding the former, they remark that often students back up to the search page without bothering to scroll through the list of the first 10 retrievals. Cockburn and McKenzie (2001) comment on the speed of the experienced computer users in their study: "Users often visit several pages within very short periods of time ... [T] he most frequently occurring time gap between subsequent page visits [i]s approximately one second, and [that] gaps of more than 10 seconds [a]re relatively rare" (p. 911).

Cooper (2001) sums up user activity in the Melvyl online catalog: "[D]isplay actions per session [a]re consistently the most frequently performed actions in the model" (p. 144). Nicholas (1995) makes the following observation about the online searches newspaper journalists make in newspaper databases, "The hallmark search is a stripped down or bare essentials one, which gives very early contact with the data and then maximum time online to browse and display records" (p. 395).

UML gateway sessions (Drabenstott, 2003, p. 842) average 27 minutes during which time searchers spend 9 minutes viewing intermediate results and 4 minutes reading fulllength digital documents. Bos et al. (2000) report comparable percentages based on an analysis of process video recordings of middle school students searching the Artemis interface to the University of Michigan digital library. Dividing 40-minute sessions into five states, they disclose that students spend about 10 minutes evaluating metadata (a similar task to scanning intermediate results) and about 7 minutes reading an average of three digital library documents.

Nicholas' (1995) suggests that users want "very early contact with the data and then maximum time online to browse and display records" (p. 395). Underlying such behavior may be users' preoccupation with recognition strategiesthey will know what they want when they see it.

\section{Satisfied With Their Online Searches}

Although research findings demonstrate that end users are not conducting very sophisticated online searches, the vast majority are satisfied with their searches. Percentages of online catalog users who express satisfaction with the results of their searches reach into the high 70s and beyond (Anderson et al., 1982, p. 11; Markey, 1984, p. 12; Matthews, 1982, p. 122; Research Libraries Group, 1982, p. 16; University of California, 1983, p. 82). This trend continues with end users who librarians train to search the same online IR systems that they themselves use for mediated searching (Haines, 1982; Sewell \& Teitelbaum, 1986), the same online IR systems through simpler front-end interfaces (Dodd, Gilreath, \& Hutchins, 1985; Mischo \& Lee, 1987; Trzebiatowski, 1984; Wildemuth \& Moore, 1995), CD-ROM databases (Bucknall \& Mangrum, 1992; Nash \& Wilson, 1991), and the Web (Fallows, 2005; Fidel et al., 1999; Rudner, 2000). Despite the high levels of satisfaction end users express with their search results, they concede that a trained intermediary searcher would do a better job (Hurt, 1983; Kirby \& Miller, 1985; Sewell \& Teitelbaum, 1986; Trzebiatowski, 1984).

Many IR researchers believe training in system use would improve end-user searching and search results (Fidel et al., 1999, p. 34; Halcoussis, Halverson, Lowenberg, \& Lowenberg, 2002, p. 154; Lancaster, Elzy, Zeter, Metzler, \& Low, 1994, pp. 383-384; Lazonder, Biemans, \& Wopereis, 2000, p. 581; Mead et al., 2000, p. 121; Hölscher \& Strube, 2000, p. 345; Nash \& Wilson, 1991, p. 90; Outsell Inc., 2000; Peters, 1991, pp. 127-141; Wolfram \& Xie, 2002, p. 644). They make this recommendation despite research findings that demonstrate end users avoid training opportunities, for example, end users hardly use the instructions systems post online (Bond, 2004, p. 258; Borgman, 1986, p. 396; Cooper, 2001, p. 146; Jones et al., 2000, p. 167; Markey, 1984, p. 129; Mischo \& Lee, 1987 , p. 247), they tell us that they search too infrequently to 
be motivated to seek training (Sewell \& Teitelbaum, 1986, p. 240), and they think they already know what they would learn from formal training (Fidel et al., 1999, p. 27; Lancaster et al., 1994, p. 382).

\section{Conclusion}

End-user searching is here to stay. People conduct millions of online searches on a daily basis. They express high levels of satisfaction with their searches. Under some conditions such as preparing a grant proposal, conducting state-of-the-art patent searches, and performing legal research, people will delegate online searching to specially trained professional search intermediaries because the cost of failure is very high and affects more people than a lone person with an information need.

End-user searches do not resemble the systematic approach of expert intermediary searchers who use the Boolean OR operator to build intermediary sets of retrievals for the unique facets of user queries and use nested Boolean logic and the Boolean AND and NOT operators to combine the retrievals in intermediary sets into a final answer set (Janes \& Walker, 1999). Hölscher and Strube (2000, p. 345) report that the number of Boolean AND operators in the searches of expert searchers may be 6 times greater than this number in searches of end users of the Fireball Web search engine. Boolean operators are also more common in the searches of end users who receive training in system use, but people need periodic refresher courses to relearn proper Boolean syntax and operator usage (Siegfried et al., 1993, p. 288).

End users enter a few short search statements into online IR systems. Generally, their queries bear two to four words. The type of search that the system will perform-an alphabetical browse, a keyword search with an implicit Boolean AND operator, or a phrase search with an implicit adjacency operator-does not seem to have an effect on the number of terms in their queries. For the vast majority of people's information needs, doing one's own searching is convenient, immediate, and instantaneous-connect to the Internet, launch a Web browser, type a query into a search engine's dialog box, browse ranked retrievals, and link to one or more full-length retrieved documents.

About the only advanced search features that figure into end-user searches on a regular basis are quotes for bound phrases and the plus $(+)$ and minus ( - ) operators. Even relevance feedback is uncommon, occurring in about $5-10 \%$ of end-user queries. A long list of IR researchers note end users seldom put advanced search features to work in their online searches (Bishop et al., 2000, p. 410; Borgman, 1986, p. 390; Cooper, 2001, p. 144; Jansen, 2005, p. 909; Jansen et al., 1998, p. 17; Larson, 1983, p. 53; Nicholas, 1995, p. 389; Peters, 1991, p. 88; Spink, Wolfram, Jansen, \& Saracevic, 2001, p. 233). Rudner (2000) sums up the situation, "End user[s] are not taking advantage of the available tools."

Examining end-user searches by the search features people use everyday makes information retrieval appear to be a very simplistic one-stop event. Part 2 picks up the discussion of research findings about end-user searching in the context of current information retrieval models that acknowledge that information retrieval is a much more complex event, involving changes in cognition, feelings, and/or events during the information-seeking process.

\section{References}

Anderson, R., Reich, V.A., Wagner, P.R., \& Zich, R. (1982). Library of Congress online public catalog users survey: A report to the Council on Library Resources. Washington, DC: Library of Congress, Office of Planning and Development.

Bishop, A.P., Neumann, L.J., Star, S.L., Merkel, C., Ignacio, E., \& Sandusky, R.J. (2000). Digital libraries: Situating use in changing information infrastructure. Journal of the American Society for Information Science, 51, 394-413.

Bond, C.S. (2004). Web users' information retrieval methods and skills. Online Information Review, 28, 254-259.

Borgman, C.L. (1983). End user behavior on the Ohio State University Libraries' online catalog: A computer monitoring study. Dublin, OH: OCLC Online Computer Library Center.

Borgman, C.L. (1986). Why are online catalogs hard to use? Lessons learned from information-retrieval studies. Journal of the American Society for Information Science and Technology, 37, 387-400.

Bos, N., Drabenstott, K.M., Krajcik, J., Soloway, E., Wooldridge, S., \& Miller, J. (2000). Students' searching and evaluating with the Artemis interface to a digital library. In Barry Fishman \& S. O'Connor-Divelbiss (Eds.), Fourth International Conference of the Learning Sciences (pp. 150-156). Mahwah, NJ: Erlbaum.

Bucknall, T., \& Mangrum, R. (1992). U-Search: A user study of the CD-ROM service at the University of North Carolina at Chapel Hill. RQ, $31,542-553$.

Cockburn, A., \& McKenzie, B. (2001). What do web users do? An empirical analysis of web use. International Journal of Human-Computer Studies, 54, 903-922.

Cooper, M.D. (2001). Usage patterns of a web-based library catalog. Journal of the American Society for Information Science and Technology, 52, 137-148.

Debowski, S. (2001). Wrong way: Go back! An exploration of novice search behaviours while conducting an information search. The Electronic Library, 19, 371-382.

Dodd, J., Gilreath, C., \& Hutchins, G. (1985). A comparison of two enduser operated search systems: Final report (ED 255224). Washington, DC: Office of Management Studies, Association of Research Libraries.

Doszkocs, T. (1983). CITE NLM: Natural-language searching in an online catalog. Information Technology and Libraries, 2, 364-380.

Drabenstott, K.M. (2003). Do non-domain experts enlist the strategies of domain experts? Journal of the American Society for Information Science and Technology, 54, 836-854.

Drabenstott, K.M., \& Vizine-Goetz, D. (1994). Using subject headings for online retrieval. San Diego: Academic Press.

Fallows, D. (2005). The Internet and daily life: Many Americans use the Internet in everyday activities, but, traditional offline habits still dominate. Washington, DC: Pew Internet \& American Life Project. Retrieved March 22, 2007, from http://www.pewinternet.org/PPF/r/131/report_display.asp

Fidel, R., Davies, R.C., Douglas, M.H., Holder, J.K., Hopkins, C.J., Kushner, E.J., et al. (1999). A visit to the information mall: Web searching behavior of high school students. Journal of the American Society for Information Science and Technology, 50, 24-37.

Haines, J.S. (1982). Experiences in training end-user searchers. Online, 6, 14-23.

Halcoussis, D., Halverson, A.L., Lowenberg, A.D., \& Lowenberg, S. (2002). An empirical analysis of web catalog user experiences. Information Technology and Libraries, 21, 148-157.

Hildreth, C.R. (1983). To Boolean or not to Boolean. Information Technology and Libraries, 2, 235-237. 
Hölscher, C., \& Strube, G. (2000). Web search behavior of Internet experts and newbies. Computer Networks, 33, 337-346.

Hsieh-Yee, I. (1993). Effects of search experience and subject knowledge on the search tactics of novice and experienced searchers. Journal of the American Society for Information Science and Technology, 44, 161-174.

Hurt, C.D. (1983). Intermediaries, self-searching and satisfaction. In M.E. Williams, \& T.H. Hogan (Eds.), Proceedings of the 4th National Online Meeting (pp. 231-238). Medford, NJ: Learned Information.

Janes, J., \& Walker, G. (1999). Online retrieval: A dialogue of theory and practice (2nd ed.). Littleton, CO: Libraries Unlimited.

Jansen, B.J. (2005). Seeking and implementing automated assistance during the search process. Information Processing and Management, 41, 909-928.

Jansen, B.J., Spink, A., Batcman, J., \& Saracevic, T. (1998). Real life information retrieval: A study of user queries on the web. SIGIR Forum, $32,1,5-17$.

Jansen, B.J., Spink, A., \& Saracevic, T. (2000). Real life, real users, and real needs: A study and analysis of user queries on the web. Information Processing and Management, 36, 207-227.

Jones, S., Cunningham, S.J., McNab, R., \& Boddie, S. (2000). A transaction $\log$ analysis of a digital library. International Journal of Digital Libraries, 3, 152-169.

Keily, L. (1997). Improving resource discovery on the Internet: The user perspective. In D.I. Raitt, P. Blake, \& B. Jeapes (Eds.), Proceedings of the 21st Online Information Meeting (pp. 205-212). Oxford: Learned Information Europe.

Kern-Simirenko, C. (1983). OPAC user logs: Implications for bibliographic instruction. Library Hi Tech, 1, 3, 27-35.

King, N.S. (1991). Search characteristics and the effects of experience on end users of PaperChase. College \& Research Libraries, 52, 360-374.

Kirby, M., \& Miller, N. (1986). MEDLINE searching on Colleague: Reasons for failure or success of untrained end users. Medical Reference Services Quarterly, 5, 17-33.

Kurth, M. (1993). The limits and limitations of transaction log analysis. Library Hi Tech, 11, 2, 98-104.

Lancaster, F.W., Elzy, C., Zeter, M.J., Metzler, L., \& Low, Y.-M. (1994). Searching databases on CD-ROM: Comparison of the results of end-user searching with results from two modes of searching by skilled intermediaries. RQ, 33, 370-386.

Larson, R. (1983). Users look at online catalogs; Part 2: Interacting with online catalogs; Final report to the Council on Library Resources (ED 231 401). Berkeley, CA: University of California.

Lazonder, A.W., Biemans, H.J.A., \& Wopereis, I.G.J.H. (2000). Differences between novice and experienced users in searching information on the World Wide Web. Journal of the American Society for Information Science, 51, 576-581.

Lester, M.A. (1989). Coincidence of user vocabulary and Library of Congress subject headings: Experiments to improve subject access in academic library online catalogs. Unpublished doctoral dissertation, University of Illinois at Urbana-Champaign.

Lucas, W., \& Topi, H. (2002). From and function: The impact of query term and operator usage on Web search results. Journal of the American Society for Information Science and Technology, 53, 95-108.

Markey, K., \& Demeyer, A.N. (1986). Dewey Decimal Classification Online Project: Evaluation of a library schedule and index integrated into the subject searching capabilities of an online catalog. Dublin, OH: OCLC Online Computer Library Center.

Markey, K. (1984). Subject searching in library catalogs. Dublin, OH: OCLC Online Computer Library Center.

Markey, K. (2007). Twenty-five years of end-user searching, part 2: Future research directions. Journal of the American Society for Information Science and Technology, 58(8), 1123-1130.

Matthews, J.R. (1982). A study of six online public access catalogs: A review of findings; a final report submitted to the Council on Library Resources. Grass Valley, CA: J. Matthews and Associates.

Mead, S.E., Sit, R.A., Rogers, W.A., Jamieson, B.A., \& Rousseau, G.K. (2000). Influences of general computer experience and ages of library database performance. Behaviour \& Information Technology, 19, 107-123.
Miller, N., Kirby, M., \& Templeton, E. (1988). MEDLINE on CD-ROM: End user searching in a medical school library. Medical Reference Services Quarterly, 7, 1-13.

Mischo, W.H., \& Lee, J. (1987). End-user searching of bibliographic databases. In M.E. Williams (Ed.), Annual Review of Information Science and Technology (pp. 227-263). Washington, DC: American Society for Information Science.

Mitev, N.N., Venner, G.M., \& Walker, S. (1985). Designing an online public access catalogue. London: The British Library.

Nash, S., \& Wilson, M.C. (1991). Value-added bibliographic instruction. Reference Services Review, 19, 1, 87-92.

Nicholas, D. (1995). Are information professionals really better online searchers than end-users (and whose story do you believe?). In D.I. Raitt \& B. Jeapes (Eds.), Proceedings of the 19th International Online Information Meeting Proceedings (pp. 383-397). Oxford: Learned Information Europe

Outsell Inc. (2000). Today's students, tomorrow's FGUs. Information About Information Briefing, 3, 24, 1-25.

Ozmutlu, S., Ozmutlu, H.C., \& Spink, A. (2003). Are people asking questions of general web search engines? Online Information Review, 27, 396-406.

Ozmutlu, S., Spink, A., \& Ozmutlu, H.C. (2003). Multimedia web searching trends: 1997-2001. Information Processing and Management, 39, 611-621.

Ozmutlu, S., Spink, A., \& Ozmutlu, H.C. (2004). A day in the life of web searching: An exploratory study. Information Processing and Management, 40, 319-345.

Peters, T.A. (1989). When smart people fail: An analysis of the transaction $\log$ of an online public access catalog. Journal of Academic Librarianship, 15, 267-273.

Peters, T.A. (1991). The online catalog: A critical examination of public use. Jefferson, NC: McFarland.

Pew Research Center. (2003). America's online pursuits: The changing picture of who's online and what they do. Washington, DC: The Center. Retrieved September 5, 2005, from http://www.pewinternet.org/reports/ toc. asp?Report $=106$

Research Libraries Group. (1982). Public online catalogs and research libraries: Final report to the Council on Library Resources. Stanford, CA: Author.

Rudner, L. (2000). Who is going to mine digital library resources? And how? D-Lib Magazine 6(5). Retrieved March 22, 2007, from http://www. dlib.org/dlib/may00/rudner/05rudner.html

Sewell, W., \& Teitelbaum, S. (1986). Observations of end-user online searching behavior over eleven years. Journal of the American Society for Information Science, 37, 234-245.

Sherman, C. (2006). Neilsen NetRatings search engine ratings. Retrieved March 22, 2007, from http://searchenginewatch.com/showPage.html? page $=2156451$

Siegfried, S., Bates, M.J., \& Wilde, D.N. (1993). A profile of end-user searching behavior by humanities scholars: The Getty Online Searching Project Report No. 2. Journal of the American Society for Information Science, 44, 273-291.

Silverstein, C., Brin, S., Motwani, R., \& Ullman, J.D. (1999). Analysis of a very large web search engine query log. SIGIR Forum, 33, 3, 6-12.

Spink, A., \& Gunar, O. (2001). E-Commerce web queries: Excite and Ask Jeeves study. First Monday. Retrieved March 22, 2007, from http://www. firstmonday.dk/issues/issue6_7/spink/index.html

Spink, A., Jansen, B.J., Wolfram, D., \& Saracevic, T. (2002). From e-sex to e-commerce: web search changes. Computer, 35, 3, 107-109.

Spink, A., \& Ozmutlu, H.C. (2002). Characteristics of question format web queries: An exploratory study. Information Processing and Management, $38,453-471$

Spink, A., Ozmutlu, H.C., \& Lorence, D.P. (2004). Web searching for sexual information: An exploratory study. Information Processing and Management, 40, 113-123.

Spink, A., Wolfram, D., Jansen, M.B.J., \& Saracevic, T. (2001). Searching the web: The public and their queries. Journal of the American Society for Information Science and Technology, 52, 226-234. 
Sutcliffe, A.G., Ennis, M., \& Watkinson, S.J. (2000). Empirical studies of end-user information searching. Journal of the American Society for Information Science, 51, 1211-1231.

Tolle, J.E. (1983). Current utilization of online catalogs: Transaction log analysis. Dublin, OH: OCLC Online Computer Library Center.

Trzebiatowski, E. (1984). End user study on BRS/Afterdark. RQ, 23, 446-450.

University of California. (1983). Users look at online catalogs: Results of a national survey of users and non-users of online public access catalogs; final report to the Council on Library Resources. Berkeley, CA: University of California Systemwide Administration, Division of Library Automation and Library Research and Analysis Group.

Vakkari, P., Pennanen, M., \& Serola, S. (2003). Changes of search terms and tactics while writing a research proposal: A longitudinal case study. Information Processing and Management, 39, 445-463.
Wallace, R., \& Kupperman, J. (1997, March). On-line search in the science classroom: Benefits and possibilities. Paper presented at the Annual Meeting of the American Educational Research Association, Chicago, IL.

Wang, P., Berry, M.W., \& Yang, Y. (2003). Mining longitudinal web queries: Trends and patterns. Journal of the American Society for Information Science and Technology, 54, 743-758.

Wiberley, S.E., Daugherty, R.A., \& Danowski, J.A. (1993). User persistence in displaying LUIS postings: A report to the Council on Library Resources. Chicago: University of Illinois at Chicago.

Wildemuth, B., \& Moore, M.E. (1995). End-user search behaviors and their relationship to search effectiveness. Bulletin of the Medical Library Association, 83, 294-304.

Wolfram, D., \& Xie, H.I. (2002). Traditional IR for web users: A context for general audience digital libraries. Information Processing and Management, 38, 627-648. 